\title{
Identification of Gene Candidates Associated with Huanglongbing Tolerance, Using 'Candidatus Liberibacter asiaticus' Flagellin 22 as a Proxy to Challenge Citrus
}

\author{
Qingchun Shi, ${ }^{1}$ Vicente J. Febres, ${ }^{2}$ Shujian Zhang, ${ }^{1}$ Fahong $\mathrm{Yu},{ }^{3}$ Greg McCollum, ${ }^{1}$ David G. Hall, ${ }^{1}$ \\ Gloria A. Moore, ${ }^{2}$ and Ed Stover ${ }^{1, \dagger}$ \\ ${ }^{1}$ U.S. Horticultural Research Laboratory, USDA/ARS, Fort Pierce, FL, U.S.A.; ${ }^{2}$ Horticultural Sciences Department, University of \\ Florida, Gainesville, FL, U.S.A.; and ${ }^{3}$ Interdisciplinary Center for Biotechnology Research, University of Florida
}

Accepted 7 September 2017.

\begin{abstract}
The 22-amino acid (flg22) pathogen-associated molecular pattern from the flagellin of Xanthomonas citri subsp. citri has been shown to induce defense responses correlated with citrus canker resistance. Here, flg22 of 'Candidatus Liberibacter asiaticus', the putative causal agent of Huanglongbing (HLB), elicited differential defense responses that were weaker than those from Xcc-flg22, between those of the HLB-tolerant mandarin cultivar Sun Chu Sha and susceptible grapefruit cultivar Duncan. Transcriptomics was used to compare the effect of CLas-flg22 and Xcc-flg22 between the citrus genotypes and identified 86 genes induced only by CLas-flg22 in the tolerant mandarin. Expression of 16 selected genes was validated, by reverse transcription-quantitative polymerase chain reaction, and was evaluated in citrus during ' $\mathrm{Ca}$. L. asiaticus' infection. Differential expression of a number of genes occurred between tolerant and susceptible citrus infected with ' $\mathrm{Ca}$. L. asiaticus', suggesting their involvement in HLB tolerance. In addition, several genes were similarly regulated by CLas-flg22 and ' $\mathrm{Ca}$. L. asiaticus' treatments, while others were oppositely regulated in the tolerant mandarin, suggesting similarity and interplay between CLas-flg22 and ' $\mathrm{Ca}$. L. asiaticus'-triggered defenses. Genes identified are valuable in furthering the study of HLB tolerance mechanisms and, potentially, for screening for HLBtolerant citrus using CLas-flg22 as a pathogen proxy.
\end{abstract}

Huanglongbing (HLB) is an endemic bacterial disease in citrus, one of the most important crops for global fresh and processed fruit markets. In the last decade, severe HLB has greatly compromised the Florida citrus industry and threatened additional producing areas in the United States and other parts of the world. The agent associated with HLB in the United States is 'Candidatus Liberibacter asiaticus', which is a gram-negative, intracellular bacterium. Vectored by the Asian citrus psyllid (ACP) (Diaphorina citri), 'Ca. L. asiaticus' can live systemically in citrus phloem cells, in which the infection compromises

${ }^{\dagger}$ Corresponding author: Ed Stover; E-mail: Ed.Stover@ARS.USDA.GOV

*The $\boldsymbol{e}$-Xtra logo stands for "electronic extra" and indicates that three supplementary figures and four supplementary tables are published online.

This article is in the public domain and not copyrightable. It may be freely reprinted with customary crediting of the source. The American Phytopathological Society, 2018. transport of photosynthetic products (Schneider 1968). 'Ca. L. asiaticus' has not been consistently cultured (Parker et al. 2014; Sechler et al. 2009), which makes studies related to hostpathogen interactions difficult. However, the completion of genomic sequencing of the ' $\mathrm{Ca}$. L. asiaticus' strain psy62 and, later, the 'Candidatus Liberibacter americanus' strain São Paulo have contributed to better understanding of these bacterial species (Duan et al. 2009; Wulff et al. 2014). In the ' $C a$. L. asiaticus' genome, no obvious pathogenicity factors could be identified that are commonly found in other pathogenic bacteria, such as genes encoding the type III secretion system components or hostcolonizing degradative enzymes delivered by type II secretion (Duan et al. 2009). However, a recent study identified 16 putative proteins in ' $\mathrm{Ca}$. L. asiaticus' with the signatures of secreted effectors, and one (CLIBASIA_05315) was shown to induce cell death in a non-'Ca. L. asiaticus' host, Nicotiana benthamiana, when transiently expressed (Pitino et al. 2016), indicating the capability for host modulation by this bacterium.

In the ' $\mathrm{Ca}$. L. asiaticus' genome, a total of 30 genes were found to encode for flagella biosynthesis (Duan et al. 2009), including a flagellin gene containing the putative 22-amino acid pathogenassociated molecular pattern (PAMP) (flg22). Flagellar assembly associated genes have been detected in gene-expression studies (Yan et al. 2013). Moreover, starch accumulation and callose deposition observed in ' $\mathrm{Ca}$. L. asiaticus'-infected phloem cells may have an association with or be a result of ' $\mathrm{Ca}$. L. asiaticus' PAMP-triggered defense responses in citrus hosts (Gómez-Gómez et al. 1999; Schneider 1968).

To date, there is no true HLB resistance found in commercially grown citrus scion cultivars. However, HLB tolerance in the form of mild symptoms and little developmental impairment has been shown in certain citrus genotypes (Cheema et al. 1982; Folimonova et al. 2009; Halbert and Manjunath 2004; Stover and McCollum 2011; Stover et al. 2016a and b). A comparative study on the defense responses of HLB-sensitive and -tolerant citrus genotypes may be helpful in the identification of one or more host factors important to HLB tolerance. A previous study on PAMP-triggered immunity (PTI) between canker (Xanthomonas citri subsp. citri)-resistant and -susceptible citrus indicated that Xcc-flg22-initiated PTI is an essential component of total resistance (Shi et al. 2015b). Interestingly, the flg22 domain from ' $\mathrm{Ca}$. L. asiaticus' (CLas-flg22) has a number of variations relative to potent elicitors, such as those found in flg22 from Xanthomonas and Pseudomonas bacteria, but shows high homology to seemingly inactive forms of flg22 such as the one 
from Agrobacterium tumefaciens (Felix et al. 1999). With only a 3-amino acid variation from Agrobacterium flg22, CLas-flg22, along with the same domain from the closely related 'Candidatus Liberibacter solanacearum' (CLso-flg22), have been shown to induce callose deposition when infiltrated into leaves of tobacco (Nicotiana benthamiana), tomato, and potato (Hao et al. 2014; Zou et al. 2012). However, the defense-eliciting activity of CLasflg22 in citrus and whether its host interaction affects disease resistance and tolerance has not been fully investigated.

Transcriptomics is a powerful tool to study global gene transcriptional variations and it has been used to analyze host reactions to infection by plant pathogens. In citrus, transcriptomics has been exploited to compare host response between ' $\mathrm{Ca}$. L. asiaticus'-infected and -uninfected fruit and leaf samples and between HLB-tolerant and -susceptible genotypes (Mafra et al. 2013; Martinelli et al. 2012, 2013; Wang et al. 2016). These studies provided insight into host physiological damage caused by infection and activation of defense mechanisms that may be associated with tolerance. However, study of early molecular events during establishment of ' $\mathrm{Ca}$. L. asiaticus' is challenging due to the fastidious nature of ' $\mathrm{Ca}$. L. asiaticus' and the irregularity of infection. As an alternative, dissection of PTI from total host immunity may simplify such studies. In Arabidopsis, Affymetrix array analysis identified early (30 to $60 \mathrm{~min}$ after treatment) flg22-regulated genes, some of which were also shown to be induced in the resistance $(R)$ gene-mediated response (Navarro et al. 2004). In another study, flagellin-induced tomato genes, which are repressed by Pseudomonas syringae effector genes, were studied using RNA sequencing (RNA-seq), which indicated a set of immunity-related genes, including a cell wall-associated kinase (SiWAK1) essential to induction of PTI (Rosli et al. 2013).

In the present study, the PAMP activity of CLas-flg22 was examined through analyzing the expression of a series of citrus defense-associated genes and reactive oxygen species (ROS) (Shi et al. 2015b). The comparison was made between the moderately HLB-tolerant mandarin cultivar Sun Chu Sha (Citrus reticulata Blanco) and the susceptible grapefruit cultivar Duncan (C. paradisi Macf.) (Folimonova et al. 2009). The response of these two cultivars to CLas-flg22 was also compared with the responses to the potent defense elicitor Xcc-flg22. Comparative transcriptomics were subsequently performed between the response to the two PAMPs and the two citrus genotypes to identify genes that were regulated by CLas-flg22 in Sun Chu Sha mandarin but not by Xcc-flg22 or in Duncan grapefruit. Selected genes were subjected to validation by reverse transcription-quantitative polymerase chain reaction (RT-qPCR) and to expression evaluation following ' $\mathrm{Ca}$. L. asiaticus' infection. We identified citrus genes induced by both CLas-flg22 and ' $\mathrm{Ca}$. L. asiaticus' challenges in the tolerant citrus, suggesting an interplay between CLas-flg22triggered defense and ' $\mathrm{C} a$. L. asiaticus' tolerance. The functions of the genes are discussed for their roles in citrus defense against ' $\mathrm{Ca}$. L. asiaticus' and possible use as marker genes to screen for HLB tolerance.

\section{RESULTS}

\section{CLas-flg22 elicits defense in citrus that is weaker than Xcc-flg22.}

The flg22 domain in the ' $\mathrm{Ca}$. L. asiaticus' flagellin protein is highly homologous with Agrobacterium tumefaciens flg22 and closely related bacterial species including ' $\mathrm{Ca}$. L. solanacearum' and Liberibacter crescens, with only a 3-amino acid difference from each of these species (Fig. 1). However, compared with the potent defense-eliciting flg22s, CLas-flg22 has 11 amino acids different from flg22 of Pseudomonas syringae pv. tabaci, and 12 amino acids different from flg22 of Xanthomonas citri subsp. citri, respectively (Fig. 1).
A previous study showed that flg22 from $X$. citri subsp. citri (causal agent of citrus canker) triggered differential defense responses between citrus canker-resistant Sun Chu Sha mandarin and susceptible Duncan grapefruit, including induction of defense-associated genes (Shi et al. 2015b). Here CLas-flg22 was used to challenge the same two citrus genotypes, which also differ in HLB tolerance. The expression of flg22responsive genes was analyzed and results indicated that PTI and effector-triggered immunity (ETI) perception and signaling genes EDR1, EDS1, NDR1, PBS1, RAR1, and SGT1, salicylic acid (SA) metabolism-related $P A L 1$ and $A Z I 1$, transcriptional regulators $N P R 2$ and $N P R 3$, and pathogenesis-related (PR) gene $R d R p 1$ were significantly upregulated $24 \mathrm{~h}$ after treatment in the moderately HLB-tolerant Sun Chu Sha mandarin (Fig. 2A). However, only a PR gene, $P R 1$, was significantly induced by CLasflg22 in the highly HLB-susceptible Duncan grapefruit (Fig. 2B).

The expression levels of PTI marker genes WRKY22 and GSTI (Asai et al. 2002) were also used to compare the responses triggered by CLas-flg22 and Xcc-flg22. It was previously shown that Xcc-flg22 upregulated these two marker genes at $24 \mathrm{~h}$ after treatment in Sun Chu Sha mandarin but not in Duncan grapefruit (Shi et al. 2015b). Hence, we used Sun Chu Sha mandarin to compare the defense-eliciting capacity between CLas-flg22 and Xcc-flg22. The results indicated that CLas-flg22 also significantly increased the expression of WRKY22 and GST1 $24 \mathrm{~h}$ after treatment, but the levels induced were lower than those induced by Xcc-flg22 (Fig. 3A and B). The expression of citrus flagellin-flg22 receptor genes $F L S 2-1$ and $F L S 2-2$ (Shi et al. 2016) was also measured in response to the two elicitors. Similarly, CLas-flg22 treatment upregulated the expression of FLS2-1 and FLS2-2 at $24 \mathrm{~h}$ but to levels significantly lower than those resulting from the treatment with Xcc-flg22 (Fig. 3C and D). In addition, ROS production as an indicator of early PTI was measured. Xcc-flg22 at the concentration of $100 \mathrm{nM}$ induced a significantly higher level of ROS compared with the control in Sun Chu Sha mandarin, and $10 \mu \mathrm{M}$ triggered a similar level of ROS (Fig. 3E). There was no significant induction of ROS by CLas-flg22 in Sun Chu Sha mandarin, even with $10 \mu \mathrm{M}$ of flg22 (Fig. 3E).

\section{CLas-flg22 triggered differential transcriptional reprogramming from $\mathrm{Xcc}-\mathrm{flg} 22$ in citrus.}

The effects of Xcc-flg22 and CLas-flg22 on the transcriptomes of Sun Chu Sha mandarin and Duncan grapefruit were compared. First, the effect of CLas-flg22 on the expression of PTI markers was evaluated at 6,12 , and $24 \mathrm{~h}$ and 2 and 3 days after the treatment in the HLB-tolerant Sun Chu Sha mandarin. Results indicated a significant upregulation of WRKY22 and GST1 at 6, 12, and $24 \mathrm{~h}$, but not at 2 or 3 days (Supplementary Fig. S1). In the previous kinetic study of citrus responses to Xcc-flg22, the

$\begin{array}{rll} & & 1 \\ \text { Agt-flg22 } & \text { (1) ARVSSGLRVGDASDNAAYWSIA } \\ \text { CLso-flg22 } & \text { (1) DRVSSGLRVADSSDNAYYWSIA } \\ \text { CLas-flg22 } & \text { (1) DRVSSGLRVSDAADNAAYWSIA } \\ \text { LCr-flg22 } & \text { (1) ERISSGLRVADAADNAAYWIA } \\ \text { Pst-flg22 } & \text { (1) TRLSSGLKINSAKDDAAGLIA } \\ \text { XCC-flg22 } & \text { (1) QRLSSGLRINSAKDDAAGLAIS }\end{array}$

Fig. 1. Comparison of the flg22 domains in the flagellin proteins from Agrobacterium tumefaciens (Agt) (NCBI accession WP_010970970), 'Candidatus Liberibacter solanacearum' (CLso) (NCBI accession KQC49213), 'Candidatus Liberibacter asiaticus' (CLas) (NCBI accession WP_015452627), Liberibacter crescens (Lcr) (NCBI accession WP_015273370), Pseudomonas syringae pv. tabaci (Pst) (NCBI accession KIY19843), and Xanthomonas citri subsp. citri (Xcc) (NCBI accession AKM25066). The amino acid sequences were aligned with AlignX from the Vector NTI package (Thermo Fisher Scientific) 
treatment of Xcc-flg22 upregulated the expression of WRKY22 and GST1 at 24 and $72 \mathrm{~h}$ but not at 6 or $120 \mathrm{~h}$ after the treatment in the canker-resistant species (Shi et al. 2015b). Hence, $24 \mathrm{~h}$ was selected as the consistent timepoint for citrus transcriptome response to CLas-flg22 and Xcc-flg22.

RNA samples were prepared $24 \mathrm{~h}$ after treatment from three biological replicates for leaf infiltration of Xcc-flg22, CLasflg22, and water control in Sun Chu Sha mandarin and Duncan grapefruit. An average of 55.2 million reads per sample were generated, with 24.8 million reads per sample (44.9\%) uniquely mapped to the Citrus clementina reference genome (Wu et al. 2014) (Supplementary Table S1). The calculation of reads per kilobase per million (RPKM) was performed to avoid gene expression bias due to sequencing depth and transcript length differences among replicates and between treatments. The results indicated constant average RPKM values (about 4.7) from all samples studied. The mapped reads were then analyzed for differentially expressed genes (DEGs), based on four pairs of comparisons with biological replicates, i.e., Xcc-flg22 to control and CLas-flg22 to control in Sun Chu Sha mandarin, Xcc-flg22 to control and CLas-flg22 to control in Duncan grapefruit (Fig. 4), with correlation between read counts and gene expression fold change shown in Supplementary Figure S2. The threshold of adjusted $P$ value 0.2 was applied to limit false discoveries from multiple comparisons, and DEGs were selected with $P<$ 0.05 and fold change $>2\left(\log _{2}\right.$ [fold change] $\left.>1,<-1\right)$. In Sun Chu Sha mandarin, a total of 2,549 DEGs were identified from the Xcc-flg22 treatment and 783 DEGs from the CLas-flg22 treatment. In Duncan grapefruit, 815 DEGs were identified from the Xcc-flg22 treatment and only one DEG from the CLasflg22 treatment (Fig. 4). The results showed that the total number of DEGs and the number of up- and downregulated DEGs were higher in response to Xcc-flg22 than to CLas-flg22 and higher in Sun Chu Sha mandarin than in Duncan grapefruit (Fig. 4).

\section{Identification of DEGs induced only by CLas-flg22} in the HLB-tolerant Sun Chu Sha mandarin.

The DEGs from the four comparisons were represented in a Venn diagram (Fig. 5). Results showed Xcc-flg22 treatment

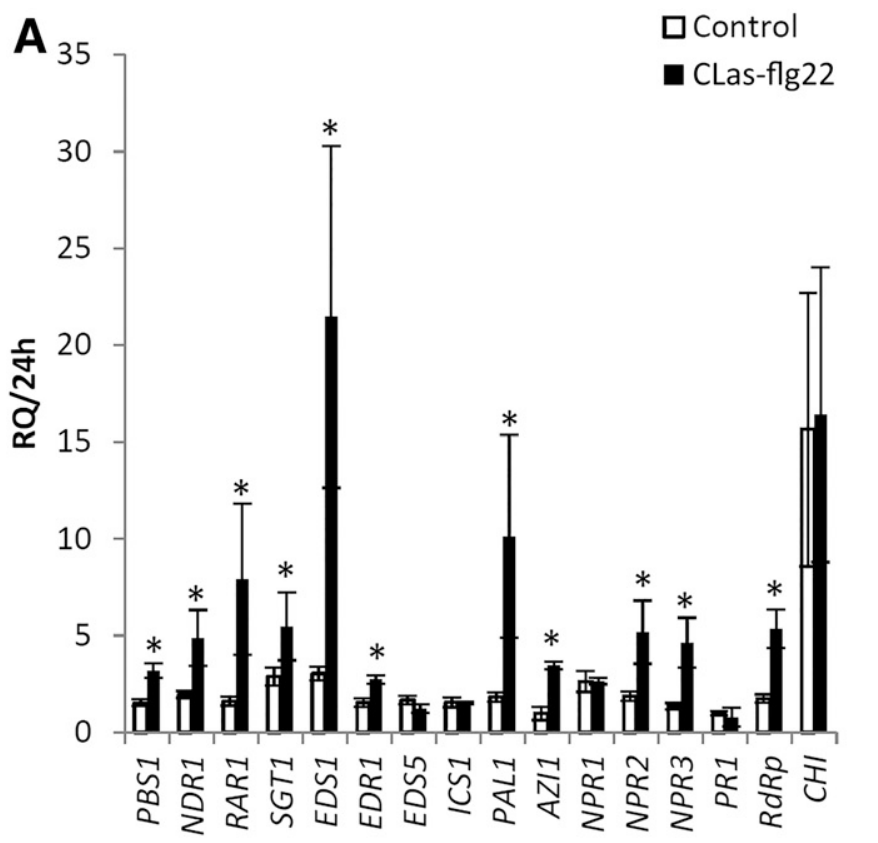

induced 1,966 DEGs in Sun Chu Sha mandarin that were not induced in Duncan grapefruit, and these DEGs include genes likely associated with citrus canker resistance (Shi et al. 2015b). Similarly, DEGs regulated by CLas-flg22 only in the HLB-tolerant Sun Chu Sha mandarin likely have roles in HLB tolerance. Both Xcc-flg22 and CLas-flg22 elicited extensive host responses in Sun Chu Sha mandarin, inducing 2,549 DEGs and 783 DEGs, respectively (Figs. 4 and 5). In this host, there were 692 DEGs induced by both flg22 elicitors and 91 DEGs induced by CLas-flg22 only, of which 86 were not induced in susceptible Duncan grapefruit (Supplementary Table S2; Fig. 5). These 86 DEGs, induced exclusively by CLas-flg22 in the tolerant genotype, were functionally categorized using gene ontology (GO) terms. Among the highly ranked functions by the number of genes, $27.4 \%$ of DEGs were nucleus related, $27.4 \%$ were extracellular-related, $21.9 \%$ were plasma membranerelated, $13.7 \%$ were cell wall-related, and $13.7 \%$ were chloroplastrelated genes (Supplementary Fig. S3). These genes specifically responsive to CLas-flg22 may be connected to host tolerance to HLB and, hence, were selected for further study for their potential association with HLB resistance/tolerance.

\section{Expression validation of selected DEGs by RT-qPCR.}

A total of 16 genes were selected from the CLas-flg22-responsive DEGs in Sun Chu Sha mandarin for expression validation by RT-qPCR. These genes included the nine most highly upregulated DEGs and the seven most highly downregulated DEGs. All 16 genes showed the same up- and downregulation pattern observed in the RNA-seq analysis, following treatment with CLas-flg22 (Supplementary Table S3). When $\log _{2}$ (fold change) values were calculated and plotted against values from the RNA-seq, an $R^{2}$ value of 0.8941 was obtained (Fig. 6), confirming that the DEGs accurately reflected the transcriptomes. To validate the unique induction by CLas-flg22 in Sun Chu Sha mandarin, expression of the 16 genes were compared between CLas-flg22 and Xcc-flg22 treatments and between Sun Chu Sha mandarin and Duncan grapefruit. Results showed that genes, including Ciclev10030243m, Ciclev10025863m, Ciclev10027253m, Ciclev10006720m, Ciclev10008874m, and Ciclev10032081m, had significantly

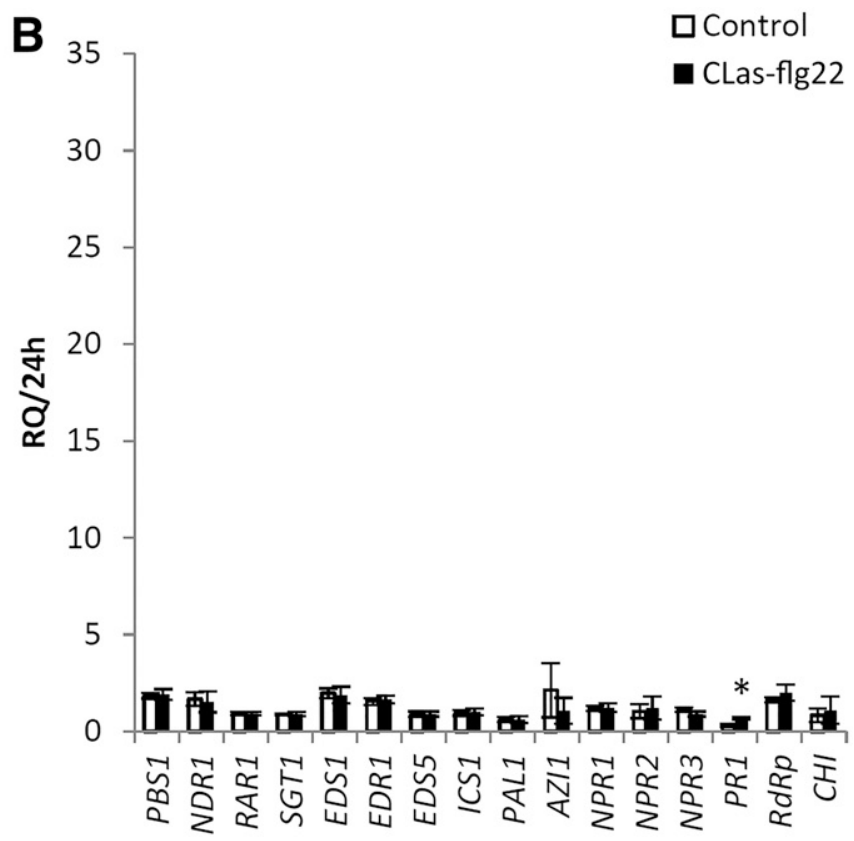

Fig. 2. The effect of CLas-flg22 $(10 \mu \mathrm{M})$ on the expression of defense-associated genes in cultivars A, Sun Chu Sha mandarin and B, Duncan grapefruit $24 \mathrm{~h}$ after treatment. Relative quantification (RQ) values are normalized with Ci5.8s as the endogenous control gene and are calculated in reference to an untreated control sample. CLas-flg22 treatment (black) are shown in comparison with the water control (white) levels. The genes studied are shown on the $x$ axis. An asterisk indicates significant difference $(P<0.05)$ between treatment and control. Bars are means \pm standard error $(n=3)$. 
increased expression, and Ciclev10019486m, Ciclev10018374m, and Ciclev10010063m had significantly reduced expression only by the treatment of CLas-flg22 in Sun Chu Sha mandarin (Fig. 7). However, the expression levels of Ciclev10030195m and Ciclev $10028437 \mathrm{~m}$ were significantly regulated by both CLasflg22 and Xcc-flg22 in Sun Chu Sha mandarin but not in Duncan grapefruit (Fig. 7), and no significant induction for Ciclev10001661m, Ciclev10007126m, Ciclev10006854m, Ciclev10026130m, and Ciclev10009893m was observed in either treatment or citrus genotypes (Fig. 7), which was different from RNA-seq results.

Evaluation of DEGs for association with HLB tolerance.

To determine if the 16 selected DEGs were also induced in citrus during HLB development, we studied their expression in citrus infected with ' $\mathrm{Ca}$. L. asiaticus', mandarin cultivar Cleopatra (similar in HLB tolerance to Sun Chu Sha mandarin), and Duncan grapefruit plants were inoculated using populations of ACP either infected or not infected (control) with ' $\mathrm{Ca}$. L. asiaticus'. Samples were collected biweekly for ' $\mathrm{Ca}$. L. asiaticus' titer estimation and gene expression analysis, for 10 weeks after inoculation (wai). ' $C a$. L. asiaticus' titers were quantified by qPCR and, in Figure 8, are expressed as $\log (16 s$ copy number). Results indicated there was a fluctuation of titer from 2 to 4 wai for both Duncan grapefruit and Cleopatra mandarin, instead of a continuous increment. Duncan grapefruit showed higher ' $\mathrm{Ca}$. L. asiaticus' titers at 2 and 4 wai but lower at 6 wai than Cleopatra mandarin (Fig. 8). However, the bacterial numbers increased to similar levels at 8 wai for the two citrus genotypes and Cleopatra mandarin had a slightly
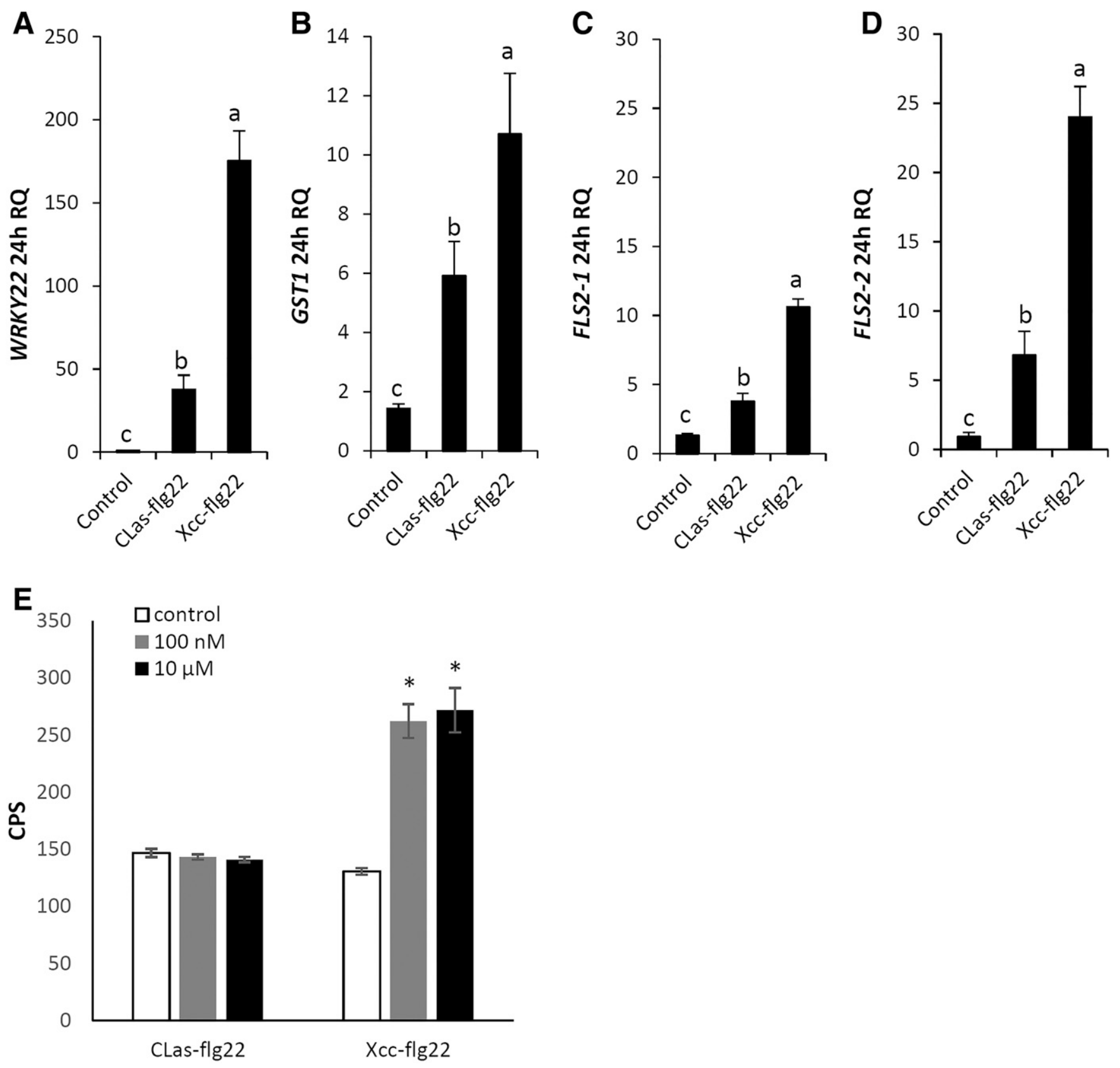

Fig. 3. The effect of CLas-flg22 and Xcc-flg22 on the expression of $\mathbf{A}$ and $\mathbf{B}, \mathrm{PTI}$ marker genes and $\mathbf{C}$ and $\mathbf{D}$, flagellin receptors, and $\mathbf{E}$, reactive oxygen species (ROS) production in Sun Chu Sha mandarin. In A to D, relative quantification (RQ) values for CLas-flg22 or Xcc-flg22 treatment or water control at $24 \mathrm{~h}$ were subject to pairwise comparisons and generation of a letter-coded statistical report. Within each plot, bars marked with the same letter were not significantly different from each other $(P<0.05)$. In $\mathrm{E}$, ROS production was measured after adding reaction solutions containing $100 \mathrm{nM}$ or $10 \mu \mathrm{M}$ of flg22 to citrus leaf discs at $0 \mathrm{~min}$. No flg22 was added to the control reactions. Luminescence was monitored as count per second (CPS) for 60 min after treatment and the peak values are shown. Values are means \pm standard error $(n=36)$. An asterisk indicates significant difference in comparison with the control. 
higher titer than Duncan grapefruit at 10 wai (Fig. 8), consistent with Cleopatra displaying HLB tolerance rather than resistance. In other work from our group, while values varied during early disease development, there were ultimately negligible differences in the ' $\mathrm{Ca}$. L. asiaticus' titer between vigorously growing tolerant mandarin hybrids and severely stunted grapefruit (Stover et al. 2016b).

Gene expression levels were compared between ' $C a$. L. asiaticus'-infected and uninfected plants at the five timepoints following infection. Induction of genes was indicated as $\log _{2}$ (fold change) values where the same thresholds were applied as in the RNA-seq analysis $\left(\log _{2}\right.$ [fold change] $>1$ or $<-1$, and $P<$ 0.05) (Table 1). In Cleopatra mandarin, ' $\mathrm{Ca}$. L. asiaticus' infection significantly increased the expression of Ciclev $10001661 \mathrm{~m}$ at 2 and 8 wai, Ciclev10007126m at 8 wai, Ciclev10032081m at 10 wai, and Ciclev10026130m at 2 and 10 wai (Table 1). Downregulations were observed in Ciclev10030243m at 6, 8, and 10 wai, Ciclev10030195m at 8 wai, Ciclev10006720m at 2 wai, Ciclev10006854m at 6 and 10 wai, Ciclev10010063m at 10 wai, and Ciclev10028437m at 2 wai. Among the DEGs, Ciclev10032081m was upregulated and Ciclev10010063m was downregulated by both CLas-flg22 and ' $\mathrm{Ca}$. L. asiaticus' challenge in mandarin (Table 1; Fig. 7). The expression of Ciclev10030243m and Ciclev10006720m, two genes upregulated by CLas-flg22 in Sun Chu Sha mandarin, showed decreased levels in the ' $\mathrm{Ca}$. L. asiaticus'-infected Cleopatra mandarin (Table 1; Fig. 7).

On the other hand, the genes studied were less responsive to ' $\mathrm{Ca}$. L. asiaticus' infection in Duncan grapefruit, as shown by fewer DEGs and fewer timepoints with significant expression changes compared with Cleopatra mandarin. However, upregulation of Ciclev10026130m at 2 and 10 wai, downregulation of Ciclev10030243m at 10 wai, Ciclev10001661m at 6 wai, Ciclev10019486m at 4 wai, and Ciclev10009893m at 10 wai were observed (Table 2).

\section{DISCUSSION}

The defense-eliciting activity of CLas-flg22 was studied in citrus and was compared with that of Xcc-flg22. CLas-flg22 induced the expression of citrus defense-associated genes including EDR1, EDS1, NDR1, PBS1, RAR1, SGT1, PAL1, AZI1, $N P R 2, N P R 3$, and RdRpl in the moderately HLB-tolerant Sun Chu Sha mandarin, but only $P R I$ was induced in the highly
HLB-susceptible Duncan grapefruit (Fig. 2). This indicates that CLas-flg22 is a PAMP for citrus that causes differential transcriptional responses in hosts with different levels of HLB tolerance. Similar results had been previously found in response to Xcc-flg22 in citrus canker-resistant and -susceptible genotypes (Shi et al. 2015b). In Sun Chu Sha mandarin, the significantly upregulated genes are thought to be involved in early molecular events that are known to be related to PTI, ETI, and nonhost resistance (Aarts et al. 1998; Azevedo et al. 2002; Fu et al. 2009; Navarro et al. 2004; Peart et al. 2002; Yun et al. 2003; Zhang et al. 2010), SA signaling and biosynthesis (Fu et al. 2012; Jung et al. 2009; MauchMani and Slusarenko 1996), cell-wall lignin biosynthesis (Rohde et al. 2004), and SAinducible antiviral defense (Xie et al. 2001). The regulation of these defense mechanisms in Sun Chu Sha mandarin but not in the HLB-sensitive Duncan grapefruit by CLas-flg22 suggest a positive correlation with HLB tolerance. However, this conclusion assumes that ' $\mathrm{Ca}$. L. asiaticus' flagellin is expressed and can be perceived by the host cell. Evidence supporting this

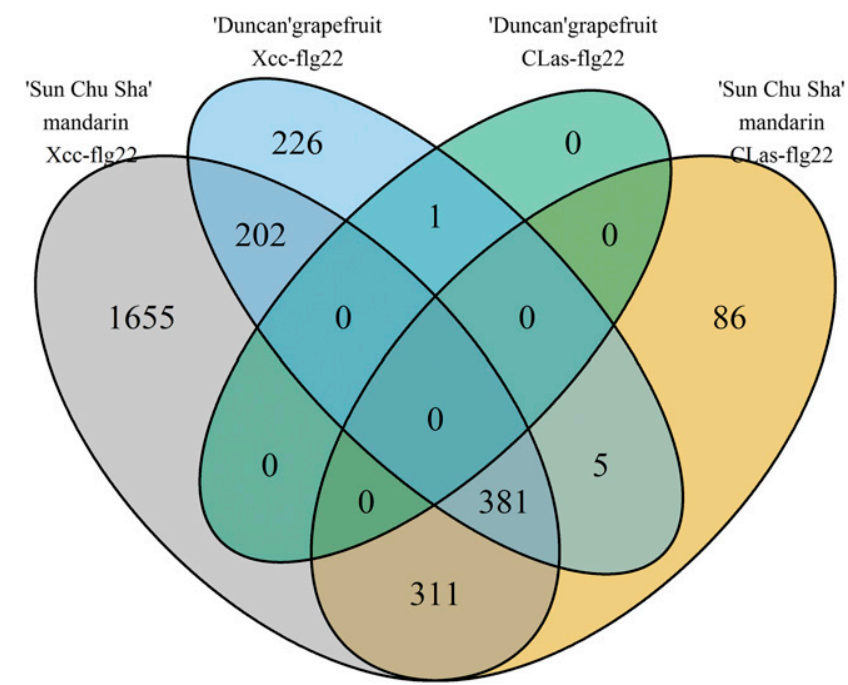

Fig. 5. Venn diagram showing the overlaps of differentially expressed genes induced by Xcc-flg22 and CLas-flg22 in Sun Chu Sha mandarin and Duncan grapefruit. The diagram was generated using JMP Genomics software (SAS Institute Inc., Cary, NC, U.S.A.).

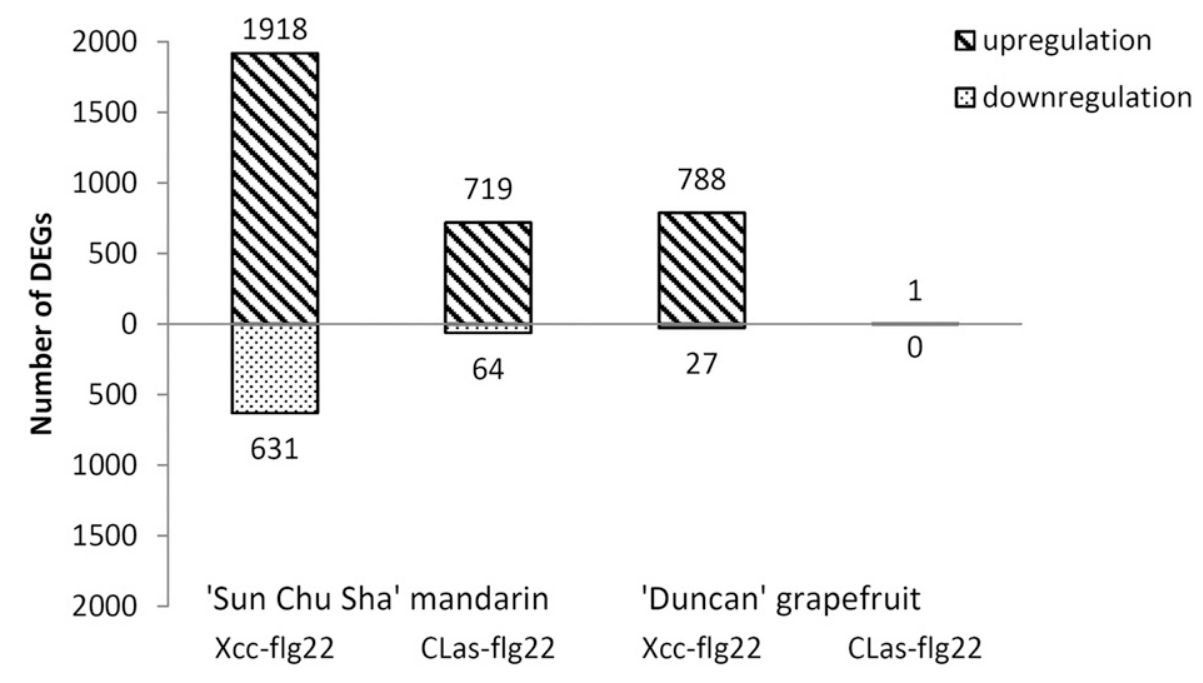

Fig. 4. Comparison of the number of differentially expressed genes (DEGs) between Xcc-flg22 and CLas-flg22 treatments in Sun Chu Sha mandarin and Duncan grapefruit. The citrus genotypes and treatments are noted under each bar, the numerical values attached to the bars indicate the number of upregulated (diagonal lines) and downregulated (dotted) DEGs. The DEGs were filtered based on adjusted $P$ value $<0.2, P<0.05$ and $\left[\log _{2}\right.$ (fold change) $>1$ or $<-1$. 
are the detection of transcript for the flagellin-encoding gene (Yan et al. 2013) and observations that Agrobacterium-mediated transient expression of ' $\mathrm{Ca}$. L. asiaticus' flagellin gene induced host callose deposition and defense-gene expressions in tobacco (Hao et al. 2014; Zou et al. 2012).

In comparison with Xcc-flg22, the levels of upregulation induced by CLas-flg22 in Sun Chu Sha were lower for WRKY22, GST1, and the flagellin receptor genes CiFLS2-1 and CiFL2-2 (Fig. 3A to D). The expression levels of these genes are reported to correspond to the strength of PTI and bacterial resistance in various citrus genotypes (Shi et al. 2016). Production of ROS was observed from Xcc-flg22 treatment of Sun Chu Sha but not from the CLas-flg22 treatments, even with the concentration as high as $10 \mu \mathrm{M}$ (Fig. 2E). These results indicate CLas-flg22 has weaker host defense-eliciting capability than Xcc-flg22 in citrus, likely reflecting differences in the amino acid sequence compared with more potent flg22s such as Xccflg22 and Pst-flg22 (Fig. 1A). Indeed, it was reported that a relatively high concentration of CLas-flg22 peptide was required to induce callose deposition in tobacco, a phenomenon associated with resistance, and that the serine (S10) and aspartic acid (D11) residues within CLas-flg22 were critical for this process (Zou et al. 2012). Because rapid ROS response is closely linked to canker resistance in citrus (Pitino et al. 2015; Shi et al. 2015b), it will be interesting to determine whether the absence or negligible levels of ROS observed during the citrus response to CLas-flg22 is due to variations in amino acids S10 and D11, in additional ones, or both, and whether this is an evolutionary consequence of a so called defense avoidance strategy (Duan et al. 2009). Similar results have been reported in that no ROS was observed when CLas-flg22 was infiltrated into leaves of tobacco, tomato, or potato (Hao et al. 2014). However, intracellular introduction of ' $\mathrm{Ca}$. L. asiaticus' flagellin whole protein by Agrobacterium-mediated transient expression resulted in production of ROS in tobacco (Hao et al. 2014). These suggest there may be either differences between extracellular and intercellular flg22 perceptions, the existence of one or more additional PAMP regions, or both (Clarke et al. 2013), in the ' $\mathrm{Ca}$. L. asiaticus' flagellin that is capable of triggering ROS. These are intriguing hypotheses to be tested.

In the present work, transcriptomics was used to identify molecular events associated with the response to CLas-flg22 and how they compared with those induced by Xcc-flg22, which has previously been shown to contribute to the resistance of another bacterial disease, citrus canker. There were more DEGs induced by Xcc-flg22 than by CLas-flg22 and more DEGs in Sun Chu Sha mandarin than in Duncan grapefruit (Fig. 3), which confirms that citrus is less responsive to CLas-flg22 than Xcc-flg22 and that the flg22-induced host response correlates with disease tolerance. Our particular interest was to study those genes induced by CLas-flg22 but not by Xcc-flg22 in the HLB-tolerant citrus genotype, which may help identify candidate genes associated with disease tolerance and uncover unique response pathways to ' $\mathrm{Ca}$. L. asiaticus'. There were 86 such DEGs identified, and they were functionally categorized based on GO. Except for DEGs with unknown function, highly ranked functions included genes related to the plasma membrane, cell wall, and chloroplast (Fig. 4), which may suggest the involvement of membrane-localized proteins for signal perception and transduction, inducible cell wall-based defense, and regulation of photosynthesis, respectively. RT-qPCR analysis of 16 of the most differentially expressed genes showed good correlation with the RNA-seq results in up- and downregulation patterns $\left(R^{2}=0.8941\right)$ (Fig. 6), and nine of these DEGs were significantly induced by the CLas-flg22 treatment only in Sun Chu Sha mandarin (Figs. 5 and 7). The genes that were not validated as CLas-flg22 uniquely responsive may be due to the statistical power and expression threshold chosen not being stringent enough during the RNA-seq data analysis. Regardless, it is known that the perception of bacterial flagellin/flg22 involves the FLS2 receptor, where binding of the ligand activates its kinase domain and turns on a series of downstream defense mechanisms (Gómez-Gómez et al. 2001; Tena et al. 2011). In comparison with Xcc-flg22, CLas-flg22 triggered host responses that differ in level (Fig. 2) and extent (Fig. 3), with some genes uniquely induced by this PAMP (Fig. 5). It is possible that differences in induced and steady-state expression levels and in protein sequence of the citrus FLS2 receptors contribute to these differential downstream responses (Shi et al. 2016). Alternatively, there may be additional receptors, functioning coordinately or independently, in the perception of this ' $\mathrm{Ca}$. L. asiaticus' flagellin epitope.

The expression of CLas-flg22 responsive DEGs were subsequently evaluated in ' $\mathrm{Ca}$. L. asiaticus'-infected plants and were compared between an HLB-tolerant and a highly susceptible



Fig. 6. Correlation between gene expression levels measured by RNA-seq and reverse transcription-quantitative polymerase chain reaction (RT-qPCR). The expression of 16 genes selected by RNA-Seq were validated by RT-qPCR. The fold change values (CLas-flg22/control in Sun Chu Sha mandarin) were transformed into $\log _{2}$ format and were plotted against those from the RNA-seq results. A correlation coefficient $\left(R^{2}\right)$ of 0.89 was obtained. 

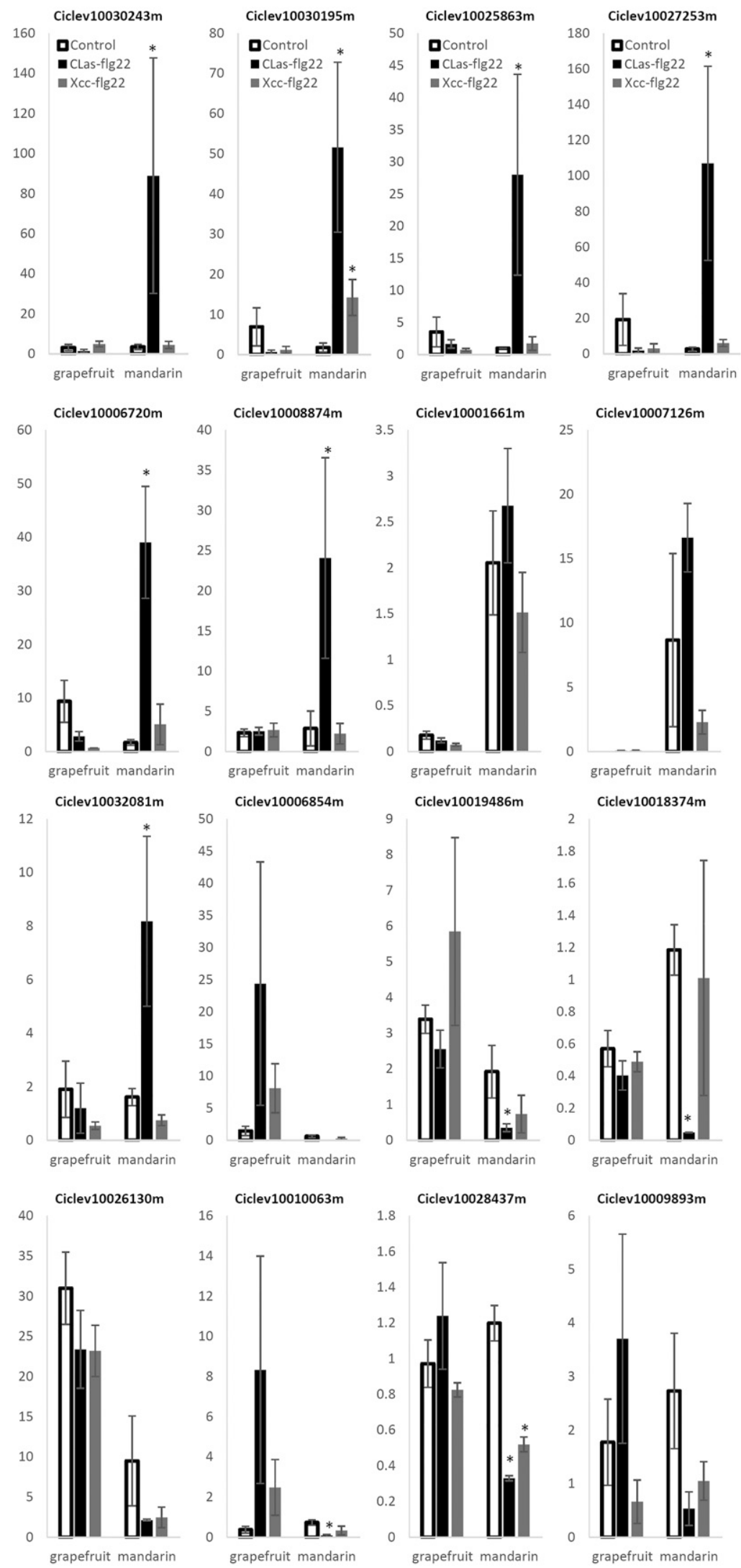

Fig. 7. Validation of selected differentially expressed genes by reverse transcription-quantitative polymerase chain reaction. Duncan grapefruit and Sun Chu Sha mandarin were infiltrated with CLas-flg22 (black), Xcc-flg22 (gray), or water (white) as the control. Samples were collected $24 \mathrm{~h}$ after the treatment, with three biological replicates. The genes studied are shown on the top of each figure. Relative quantification (RQ) values are indicated on the $y$ axis. An asterisk indicates a significant difference between treatment and control $(P<0.05)$. Bars are means \pm standard error $(n=3)$. 
citrus genotype. ' $C a$. L. asiaticus' inoculation by ACP infestation did not result in continuous increments but, rather, a fluctuation of ' $\mathrm{Ca}$. L. asiaticus' titer from 2 to 6 wai in both kinds of citrus (Fig. 8), a possible reflection of variation in bacterial transmission by ACP and uneven distribution of the bacterium in plants at an early stage of infection. There were higher bacterial numbers in Duncan grapefruit at 2 and 4 wai but lower at 6 wai than in Cleopatra mandarin, which, again, may be due to inoculum differences from ACP populations or, alternatively, a result of early tolerant response in Cleopatra mandarin. Subsequently, the ' $\mathrm{Ca}$. L. asiaticus' titer increased to similar levels in Cleopatra mandarin and Duncan grapefruit at

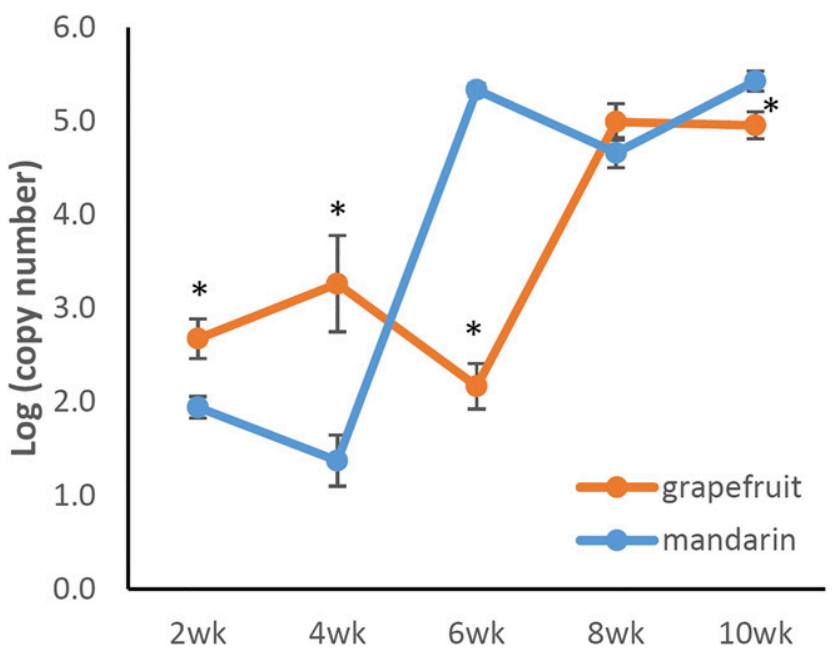

Fig. 8. Average 'Candidatus Liberibacter asiaticus' titer after Asian citrus psyllid infestation inoculation in Cleopatra mandarin and Duncan grapefruit. The bacterium titer was measured by quantitative polymerase chain reaction (qPCR) biweekly for 10 weeks after inoculation. Amplification of $16 s$, using Las-long primers from $100 \mathrm{ng}$ of DNA template, generated cycle threshold $\left(\mathrm{C}_{\mathrm{t}}\right)$ data from six biological replicates with triplication in $\mathrm{qPCR}$ test. A standard curve was determined as $\log ($ copy number $)=-0.289 \times \mathrm{C}_{\mathrm{t}}+$ 11.66 and was used to calculate ' $\mathrm{Ca}$. L. asiaticus' $16 \mathrm{~s}$ copy numbers. An asterisk indicated significant difference between mandarin and grapefruit at the same timepoint $(P<0.05)$.

Table 1. Expression change between 'Candidatus Liberibacter asiaticus'infected and -uninfected Cleopatra mandarin, based on RNA-seq results ${ }^{\text {a }}$

\begin{tabular}{|c|c|c|c|c|c|}
\hline Citrus clementina locus & 2 wai & 4 wai & 6 wai & 8 wai & 10 wai \\
\hline \multicolumn{6}{|l|}{ Upregulated by CLas-flg22 } \\
\hline Ciclev $10030243 \mathrm{~m}^{\mathrm{b}}$ & 0.76 & -1.32 & $-2.57^{\mathrm{c}}$ & $-4.03^{\mathrm{c}}$ & $-2.13^{\mathrm{c}}$ \\
\hline Ciclev10030195m & 0.94 & -0.01 & 0.32 & $-1.55^{\mathrm{c}}$ & -0.78 \\
\hline Ciclev10025863m $\mathrm{b}$ & -0.14 & -0.70 & 1.20 & -0.40 & -0.18 \\
\hline Ciclev $10027253 \mathrm{~m}^{\mathrm{b}}$ & 1.35 & 2.99 & 0.75 & -0.26 & NA \\
\hline Ciclev $10006720 \mathrm{~m}^{\mathrm{b}}$ & $-1.56^{\mathrm{c}}$ & 0.99 & -0.08 & -0.14 & 0.26 \\
\hline Ciclev $10008874 \mathrm{~m}^{\mathrm{b}}$ & 3.94 & 2.61 & 0.15 & 0.64 & 2.64 \\
\hline Ciclev10001661m & $1.43^{\mathrm{c}}$ & -0.90 & 0.15 & $1.63^{\mathrm{c}}$ & 1.24 \\
\hline Ciclev10007126m & 4.58 & 1.62 & 1.91 & $2.24^{\mathrm{c}}$ & 2.28 \\
\hline Ciclev $10032081 \mathrm{~m}^{\mathrm{b}}$ & 2.39 & -4.49 & -2.00 & -0.96 & $2.00^{\mathrm{c}}$ \\
\hline \multicolumn{6}{|c|}{ Downregulated by CLas-flg22 } \\
\hline Ciclev10006854m & -3.03 & -0.22 & $-2.39^{c}$ & -1.56 & $-2.31^{\mathrm{c}}$ \\
\hline Ciclev10019486m ${ }^{\mathrm{b}}$ & -0.38 & 0.17 & -0.92 & 0.12 & 0.55 \\
\hline Ciclev10018374m & -0.47 & 0.14 & -0.54 & 0.91 & 0.85 \\
\hline Ciclev10026130m & $1.57^{\mathrm{c}}$ & -0.40 & -0.15 & 1.71 & $1.77^{\mathrm{c}}$ \\
\hline Ciclev10010063m $\mathrm{m}^{\mathrm{b}}$ & -3.97 & -0.65 & -2.33 & -1.04 & $-1.58^{\mathrm{c}}$ \\
\hline Ciclev10028437m & $-1.66^{\mathrm{c}}$ & -0.12 & -0.19 & -0.93 & -0.06 \\
\hline Ciclev10009893m & -1.40 & -0.46 & 0.99 & 2.41 & 1.18 \\
\hline
\end{tabular}

wai $=$ weeks after inoculation

b Genes validated by reverse transcription-quantitative polymerase chain reaction that are responsive to CLas-flg22 but not Xcc-flg22 in mandarin

${ }^{c}$ Significant difference between infected and uninfected plants. Values are shown only when they are significantly regulated and $\left(\log _{2}\right.$ [fold change] $)>1$ or $<-1$.
8 wai and was slightly higher in Cleopatra mandarin at 10 wai (Fig. 8), suggesting an independence of titer development to HLB tolerance at later timepoints. Consistent reports also indicated ' $\mathrm{Ca}$. L. asiaticus' titers were similar between susceptible and tolerant citrus trees two years after field disease exposure (Stover et al. 2016b) and three months after graft inoculation under greenhouse conditions (Folimonova et al. 2009). In the gene expression analysis, ' $\mathrm{Ca}$. L. asiaticus' inoculation resulted in significant up- and downregulation in a higher number of genes and timepoints studied in Cleopatra mandarin compared with Duncan grapefruit (Tables 1 and 2), suggesting that an extensive induction of these genes may be associated with HLB tolerance. In Cleopatra mandarin, ' $\mathrm{Ca}$. L. asiaticus' induced upregulation of Ciclev10001661m, Ciclev10007126m and Ciclev10032081m, and downregulation of Ciclev10030243m, Ciclev10030195m, Ciclev10006720m, Ciclev10006854m, Ciclev10010063m and Ciclev $10028437 \mathrm{~m}$ at various timepoints, which was not observed in the susceptible Duncan grapefruit except for similar upregulation of Ciclev10030243m at smaller fold change and less timepoints (Tables 1 and 2). Examination of the function of the abovementioned genes from their Arabidopsis homologs revealed most of them are directly or indirectly involved in plant defense against pathogens and, interestingly, they also play important roles in plant development, such as germination, root growth, and floral development (Table 3). This underlines the importance of one or both interplay and balance between defense and growth during the HLB-tolerance response (Huot et al. 2014), where regulation of individual genes regarding time and duration of gene induction appears to be programmed to achieve the tolerance response.

Among the nine genes that were validated as only CLasflg22-responsive previously (Fig. 7), Ciclev10032081m and Ciclev10010063m showed the same regulation between CLasflg22 treatment and ' $\mathrm{Ca}$. L. asiaticus' inoculation, while Ciclev10030243m and Ciclev10006720m showed the opposite regulation in Cleopatra mandarin (Table 1), although there was a moderate downregulation of Ciclev $10030243 \mathrm{~m}$ only at 10 wai in Duncan grapefruit (Table 1). These results may suggest host defense activation through the perception of the PAMP of ' $\mathrm{Ca}$. L. asiaticus', which shares similarity to that induced by the whole pathogen, and moreover, ' $\mathrm{Ca}$. L. asiaticus' may have a mechanism (such as by secretion of an effector) to modulate host response and

Table 2. Expression between 'Candidatus Liberibacter asiaticus'-infected and -uninfected Duncan grapefruit, based on RNA-seq results ${ }^{\mathrm{a}}$

\begin{tabular}{|c|c|c|c|c|c|}
\hline Citrus clementina locus & 2 wai & 4 wai & 6 wai & 8 wai & 10 wai \\
\hline \multicolumn{6}{|l|}{ Upregulated by CLas-flg22 } \\
\hline Ciclev10030243m $\mathrm{m}^{\mathrm{b}}$ & 0.43 & 0.44 & -0.29 & -0.78 & $-1.63^{\mathrm{c}}$ \\
\hline Ciclev10030195m & -0.71 & 0.96 & 0.47 & 0.50 & 0.91 \\
\hline Ciclev $10025863 \mathrm{~m}^{\mathrm{b}}$ & -0.99 & 0.64 & -0.69 & -0.16 & 0.72 \\
\hline Ciclev $10027253 \mathrm{~m}^{\mathrm{b}}$ & -0.38 & 2.21 & -0.07 & 0.30 & 1.83 \\
\hline Ciclev $10006720 \mathrm{~m}^{\mathrm{b}}$ & -0.83 & 0.40 & -0.82 & 0.02 & -0.07 \\
\hline Ciclev $10008874 \mathrm{~m}^{\mathrm{b}}$ & 0.78 & 0.36 & 0.41 & 0.67 & 0.29 \\
\hline Ciclev10001661m & -0.53 & -0.95 & $-1.29^{\mathrm{c}}$ & -0.29 & 2.08 \\
\hline Ciclev10007126m & 0.99 & -0.17 & -0.59 & 0.25 & -1.59 \\
\hline Ciclev10032081 $\mathrm{m}^{\mathrm{b}}$ & -0.67 & -5.79 & -1.29 & 0.67 & 2.72 \\
\hline \multicolumn{6}{|c|}{ Downregulated by CLas-flg22 } \\
\hline Ciclev10006854m & 0.15 & 0.09 & -0.42 & 1.31 & -0.15 \\
\hline Ciclev10019486m ${ }^{\mathrm{b}}$ & -0.72 & $-1.43^{\mathrm{c}}$ & -0.76 & -0.31 & 0.34 \\
\hline Ciclev10018374m $\mathrm{m}^{\mathrm{b}}$ & -0.07 & 0.39 & 0.64 & 0.80 & 0.58 \\
\hline Ciclev10026130m & $2.23^{\mathrm{c}}$ & 0.02 & 1.22 & 0.43 & $3.87^{\mathrm{c}}$ \\
\hline Ciclev10010063m $\mathrm{m}^{\mathrm{b}}$ & 0.10 & 0.26 & 0.56 & 0.80 & -0.82 \\
\hline Ciclev $10028437 \mathrm{~m}$ & -0.60 & 0.06 & 0.36 & 0.20 & -0.43 \\
\hline Ciclev10009893m & 0.59 & -0.08 & -0.77 & -1.43 & $-1.58^{\mathrm{c}}$ \\
\hline
\end{tabular}

wai $=$ weeks after inoculation

b Genes validated by reverse transcription-quantitative polymerase chain reaction that are responsive to CLas-flg22 but not Xcc-flg22 in mandarin

c Significant difference between infected and uninfected plants. Values are shown only when they are significantly regulated and $\left(\log _{2}\right.$ [fold change] $)>1$ or $<-1$. 
suppress PAMP-triggered defense. However, it must be noted that citrus transcriptional changes to ' $\mathrm{Ca}$. L. asiaticus' infection were late responses (from 2 to 10 wai) relative to the responses to CLasflg22 (24 h), which may cause differences in gene induction between ' $\mathrm{Ca}$. L. asiaticus' (Tables 1 and 2) and CLas-flg22 challenges (Fig. 7). Additionally, while Cleopatra, used for the ' $\mathrm{Ca}$. L. asiaticus' infection comparisons, is genetically very similar to Sun Chu Sha, which was used for the CLas-flg22 studies, they are not identical. Some of the differences observed may reflect these genotypic differences. However, the commonality of gene regulation that was observed in these two studies suggests the likelihood that the same genes may also be involved in other HLB-tolerant genotypes. The evaluation of genes in other tolerant citrus species is under way.
In conclusion, we showed that CLas-flg22 is a defenseeliciting PAMP in citrus, triggering differential transcriptional responses between HLB-tolerant and highly susceptible genotypes. In comparison with Xcc-flg22, CLas-flg22 induced lower expression levels of PTI marker genes WRKY22 and GST1 and FLS2 receptor genes and did not cause ROS production as does Xcc-flg22. Comparative transcriptomics between CLas-flg22 and Xcc-flg22 treatment of both Sun Chu Sha mandarin and Duncan grapefruit identified 86 genes that were specifically responsive to CLas-flg22 in the HLB-tolerant Sun Chu Sha mandarin. A selection of 16 genes was validated via RT-qPCR and results indicated consistency $\left(R^{2}=0.89\right)$ with RNA-seq data. In the evaluation of gene expression under ' $\mathrm{Ca}$. L. asiaticus' infection, Cleopatra mandarin exhibited more significantly

Table 3. Citrus genes and loci differentially regulated by 'Candidatus Liberibacter asiaticus' infection in Cleopatra mandarin ${ }^{\mathrm{a}}$

\begin{tabular}{|c|c|c|c|c|}
\hline $\begin{array}{l}\text { Citrus clementina } \\
\text { locus }\end{array}$ & Regulation $^{\mathbf{b}}$ & Arabidopsis homolog & Biological functions in Arabidopsis & Journal citations \\
\hline Ciclev10032081m & $\mathrm{Up}$ & At5G47000; class III peroxidases & $\begin{array}{l}\text { Secreted haem-containing enzymes } \\
\text { involved in germination, cell wall } \\
\text { cross-linking and lignification, } \\
\text { reactive oxygen species generation, } \\
\text { or serving as pathogenesis-related } \\
\text { (PR) proteins. }\end{array}$ & $\begin{array}{l}\text { Almagro et al. 2009; Passardi et al. } \\
\text { 2005; van Loon et al. } 2006\end{array}$ \\
\hline Ciclev10010063m & Down & NA & NA & NA \\
\hline Ciclev10030243 $\mathrm{m}^{\mathrm{c}}$ & Down & $\begin{array}{l}\text { AT5G09530; proline-rich protein } 10 \\
\text { (PRP10); PELPK1 }\end{array}$ & $\begin{array}{l}\text { Induced by abiotic and biotic } \\
\text { stresses; involved in development: } \\
\text { transgenic gene overexpression } \\
\text { accelerates germination and root } \\
\text { growth and silencing the gene } \\
\text { resulted in slowed development in } \\
\text { comparison with the wild-type } \\
\text { plants. }\end{array}$ & $\begin{array}{l}\text { Ascencio-Ibáñez et al. 2008; Kilian } \\
\text { et al. 2007; Rashid and Deyholos } \\
\text { 2011; Sottosanto et al. } 2004\end{array}$ \\
\hline Ciclev10006720m & Down & AT5G24080; serine threonine kinase & $\begin{array}{l}\text { Expression of AT5G } 24080 \text { was } \\
\text { controlled by the mediator MED18, } \\
\text { a protein that regulates plant } \\
\text { immunity, flowering time, and } \\
\text { hormone response through } \\
\text { interactions with various } \\
\text { transcription factors. }\end{array}$ & Lai et al. 2014 \\
\hline Ciclev10006854m & Down & AT5G04010; F-box motif protein & $\begin{array}{l}\text { Protein ubiquitination; no known } \\
\text { homology for the sequence outside } \\
\text { the F-box domain. }\end{array}$ & NA \\
\hline Ciclev10001661m & $\mathrm{Up}$ & $\begin{array}{l}\text { AT5G54160; caffeic acid } \\
O \text {-methyltransferase }\end{array}$ & $\begin{array}{l}\text { Biosynthesis of melatonin, an } \\
\text { essential secondary messenger for } \\
\text { plant resistance to pathogens and } \\
\text { developmental processes including } \\
\text { root development, flowering time, } \\
\text { and biomass accumulation. }\end{array}$ & $\begin{array}{l}\text { Byeon and Back 2014; Lee et al. } \\
\text { 2014; Park and Back 2012; Shi } \\
\text { et al. 2015a }\end{array}$ \\
\hline Ciclev10007126m & $\mathrm{Up}$ & AT3G57270; $\beta$-1,3-glucanase 1 (BG 1) & $\begin{array}{l}\text { Induced by fungal infection and } \beta-1 \text {, } \\
\text { 3-glucanase extract can inhibit } \\
\text { fungal growth. Tobacco PR-2 } \\
\text { proteins are acidic isoforms of } \beta \text {-1, } \\
\text { 3-glucanases. Transcripts } \\
\text { accumulated with tobacco mosaic } \\
\text { virus infection and in the flower } \\
\text { tissues during floral development. }\end{array}$ & $\begin{array}{l}\text { Côté et al. 1991; Lotan; Ori et al. } \\
\text { 1989; Mauch et al. } 1988\end{array}$ \\
\hline Ciclev $10030195 \mathrm{~m}^{\mathrm{c}}$ & Down & $\begin{array}{l}\text { AT5G09530; proline-rich protein } 10 \\
\text { (PRP10); PELPK1 }\end{array}$ & $\begin{array}{l}\text { Induced by abiotic and biotic } \\
\text { stresses; involved in development: } \\
\text { transgenic gene overexpression } \\
\text { accelerates germination and root } \\
\text { growth and silencing the gene } \\
\text { resulted in slowed development in } \\
\text { comparison with the wild type } \\
\text { plants. }\end{array}$ & $\begin{array}{l}\text { Ascencio-Ibáñez et al. 2008; Kilian } \\
\text { et al. 2007; Rashid and Deyholos } \\
\text { 2011; Sottosanto et al. } 2004\end{array}$ \\
\hline Ciclev10028437m & Down & $\begin{array}{l}\text { AT5G59590; UDP-glucosyl transferase } \\
\text { 76E2 (UGT76E2) }\end{array}$ & $\begin{array}{l}\text { Expressed during petal differentiation } \\
\text { and expansion stage. Involved in the } \\
\text { biosynthesis of pollen-specific } \\
\text { flavonols. }\end{array}$ & Yonekura-Sakakibara et al. 2014 \\
\hline
\end{tabular}

a NA = Not available.

b Regulation by 'Ca. L. asiaticus' infection.

c Both Ciclev10030243m and Ciclev10030195m are homologous to Arabidopsis AT5G09530, but the two genes share a low level of homology to each other. Hence, primers were designed to specifically analyze each gene. 
regulated genes at more timepoints than did Duncan grapefruit, and some differentially regulated genes are likely to be HLB tolerance-related. In the comparison between CLas-flg22 treatment and ' $\mathrm{Ca}$. L. asiaticus' inoculation, we identified genes (Ciclev10032081m and Ciclev10010063m) similarly regulated between the two treatments, and genes (Ciclev10030243m and Ciclev10006720m) whose expression was upregulated by CLasflg22 but were suppressed by ' $C a$. L. asiaticus' in Cleopatra mandarin. Our study identified citrus genes correlated with HLB tolerance by using CLas-flg22 as the pathogen proxy, and these genes may prove valuable in understanding the mechanism of tolerance, interaction of CLas-flg22 induced PTI with ' $\mathrm{Ca}$. L. asiaticus' pathogenesis, and HLB-tolerance screening based on response to CLas-flg22.

\section{MATERIALS AND METHODS}

\section{Plant material.}

All the citrus plants in this study were grown in pots under greenhouse conditions. Sun Chu Sha mandarin and Duncan grapefruit plants were pruned prior to flg22 treatment and young fully expanded leaves were used for infiltration. For ACP infestation experiments, Cleopatra mandarin and Duncan grapefruit plants at a similar age were pruned to $15 \mathrm{~cm}$ tall and were grown until multiple young flushes were present.

\section{Flg22 peptide treatment.}

Flagellin conserved domains from $X$. citri subsp. citri (Xccflg22: QRLSSGLRINSAKDDAAGLAIS) and ' $\mathrm{Ca}$. L. asiaticus' (CLas-flg22: DRVSSGLRVSDAADNAAYWSIA) were synthesized by GenScript, Piscataway, NJ, U.S.A. Flg22 solutions at a concentration of $10 \mu \mathrm{M}$ were infiltrated into the abaxial surface of leaves, using a 1-ml insulin syringe with a needle until half of the leaf was saturated. Infiltration with distilled water in the same manner was used as the control. Leaf tissue was collected $24 \mathrm{~h}$ after infiltration and RNA was extracted from infiltrated areas (discussed below). Three plants were used as biological replicates for each treatment.

\section{ROS production assay.}

Leaf discs (3.8 $\mathrm{mm}$ in diameter) were obtained from young fully expanded but not hardened leaves and were kept in $200 \mu \mathrm{l}$ of sterile water overnight in a 96-well plate at room temperature. The next day, the water was replaced with $100 \mu \mathrm{l}$ of assay solution $(100 \mu \mathrm{M}$ luminol, $10 \mu \mathrm{g}$ of horseradish peroxidase per milliliter, and either $100 \mathrm{nM}$ or $10 \mu \mathrm{M}$ flg22). Assay solution without flg22 was used for controls. Luminescence (count per second, CPS) was measured for $60 \mathrm{~min}$ using the LUMIstar microplate luminometer (BMG LABTECH, Cary, NC, U.S.A.). Means and standard errors for ROS production peak values were calculated based on 36 leaf discs for each treatment. Experiments were repeated twice with similar results.

\section{RNA extraction.}

Total RNA was extracted using TriZol reagent (Invitrogen, Carlsbad, CA, U.S.A.) according to the manufacturer's instructions, followed by DNase treatment and clean up with the RNeasy plant mini kit (Qiagen, Gaithersburg, MD, U.S.A.).

\section{RNA sequencing.}

TruSeq barcoded RNA libraries were constructed at the Interdisciplinary Center for Biotechnology Research (ICBR) at the University of Florida (Gainesville, FL, U.S.A.). RNA concentration was determined using a NanoDrop spectrophotometer (Thermo Scientific, Wilmington, DE, U.S.A.), and sample quality was assessed using the Agilent 2100 Bioanalyzer (Agilent Technologies, Santa Clara, CA, U.S.A.). Two micrograms of total RNA was used for library construction using the TruSeq RNA sample preparation kit (Illumina, San Diego, CA, U.S. A.), according to manufacturer's protocol. Briefly, poly-A mRNA was enriched from $1.5 \mu \mathrm{g}$ of total RNA sample, using polydT oligo-attached magnetic beads. Purified mRNA was then fragmented using divalent cations at $94^{\circ} \mathrm{C}$, followed by firststrand cDNA synthesis using reverse transcription and random primers. Synthesis of double-stranded cDNA using DNA polymerase I and RNase $\mathrm{H}$ was performed, followed by end-repair and dA-tailing. Indexed Illumina adaptors were ligated to each sample. Finally, the library was enriched by 11 cycles of amplification and was purified by Agencourt AMPure beads (Beckman Coulter Life Sciences, Indianapolis, IN, U.S.A.). The barcoded libraries were pooled and were run using three lanes on Illumina HiSeq 2000 for $2 \times 100$ cycles.

\section{RNA-seq data DEGs analysis.}

Reads acquired from the Illumina HiSeq system were cleaned up with the Cutadapt program (Martin 2011) to trim off sequencing adaptors and low-quality bases with a quality Phredlike score smaller than 20 . Reads less than 40 bases were excluded from RNA-seq analysis. The transcripts of Citrus clementina (33,929 sequences) from the Citrus Genome database were used as reference sequences for analysis. The cleaned reads of each sample were mapped independently to the reference sequences using the mapper of Bowtie 2 (Langmead and Salzberg 2012), with a maximum of three mismatches for each read. The mapping results were processed with the SAMtools (Li et al. 2009) and scripts developed in-house at ICBR to remove potential PCR duplicates and select unique mapping reads for gene expression estimation. The number of mapped reads for each individual gene were counted and were analyzed by the DEB application (Yao and $\mathrm{Yu}$ 2011). Significantly up- and downregulated genes were selected using $P$ value, adjusted $P$ value, and fold change for downstream analysis.

\section{Gene expression by RT-qPCR.}

The RNA concentration and purity were determined using a NanoDrop spectrophotometer (Thermo Scientific). The cDNA synthesis reaction was performed using $1 \mu \mathrm{g}$ of RNA and MMLV reverse transcription (Invitrogen) with random primers. For the study of responses to flg22 treatment, gene expression was measured using the comparative cycle threshold $(\Delta \Delta \mathrm{CT})$ method (Livak and Schmittgen 2001), using TaqMan MGB probe and fast universal PCR master mix (Applied Biosystems, Foster City, CA, U.S.A.). The details in reaction settings and the sequences of gene primers have been previously described (Shi et al. 2015b). StepOnePlus software (Applied Biosystems) was used to analyze the combined study using data from multiple plates. Endogenous control gene Ci5.8s was used for data normalization. Relative quantification (RQ) values were generated by the $\Delta \Delta C T$ method, using a reference sample (calibrator) selected at random from the untreated controls.

For the study of gene expression in ' $\mathrm{Ca}$. L. asiaticus'-infected plants, the cDNA synthesis was performed using QuantiTect reverse transcription kit (Qiagen) from $1 \mu \mathrm{g}$ of RNA. SYBR green reagent (Thermo Fisher Scientific, Waltham, MA, U.S.A.) was used for RT-qPCR, following manufacturer protocols with primers (Supplementary Table S4), amplifying from $10 \mathrm{ng}$ of cDNA. The $\Delta \Delta C T$ method was applied to generate RQ values by the StepOnePlus software from six biological replicates for each treatment. Citrus glyceraldehyde-3-phosphate dehydrogenase $C 2$ (GAPC2) was used as the endogenous gene for normalization (Mafra et al. 2012), and one randomly selected sample from the ' $\mathrm{Ca}$. L. asiaticus'-negative ACP-infested group as the reference sample. Statistical significance was calculated based 
on analysis of variance $(P<0.05)$ using the $\mathrm{R}$ program (The $\mathrm{R}$ Foundation for Statistical Computing, Vienna).

\section{ACP infestation and ' $\mathrm{Ca}$. L. asiaticus' detection by qPCR.}

' $C a$. L. asiaticus'-positive and -negative adult ACP were hatched from eggs at about the same time 5 weeks before the infestation. Six citrus plants with young flushes were moved to cages with 400 ' $C a$. L. asiaticus'-positive ACP or ' $C a$. L. asiaticus'-negative ACP. ACP fed on plants for 2 weeks and were then removed by aspiration and were treated with carbaryl insecticide. Plants were maintained in the greenhouse for disease development. Samples of three to five leaves per plant were randomly collected. Midrib tissues were cut for ' $\mathrm{Ca}$. L. asiaticus' titer analysis, and the remaining leaf halves were stored for gene expression analysis. DNA was isolated from midrib tissues using the DNeasy plant mini kit (Qiagen), and the quantity and quality were determined by a NanoDrop spectrophotometer (Thermo Scientific). DNA at $100 \mathrm{ng}$ was used to test ' $\mathrm{Ca}$. L. asiaticus' titer by qPCR, with SYBR master mix (Thermo Fisher Scientific), using an ABI7500 thermal cycler (Applied Biosystems). Las-long primers (Stover et al. 2015, 2016b) were used for ' $\mathrm{Ca}$. L. asiaticus' detection with three technical replicates per sample. A standard curve was established, using ' $C a$. L. asiaticus'-positive citrus DNA with known $16 s$ gene copy number, and generated the linear regression of $\log ($ copy number $)=-0.289 \times \mathrm{C}_{\mathrm{t}}+11.66\left(R^{2}=\right.$ 0.9997).

\section{ACKNOWLEDGMENTS}

We thank K. Niblett, E. Cochrane, Y. Avila, K. Moulton, C. Veith, M. Geraghty, I. Meservey, and S. Durden for their technical assistance. Our thanks also go to C. Chase for use of her luminometer, J. Chaparro for the Sun Chu Sha mandarin material and S. Zhang for the data statistical analysis. Funding was provided by the Citrus Research and Development Foundation (CRDF), Inc., Lake Alfred, FL, U.S.A. The authors declare that they have no conflicts of interest. USDA is an equal opportunity provider and employer. Mention of trade names or commercial products in this article is solely for the purpose of providing specific information and does not imply recommendation or endorsement by the United States Department of Agriculture.

\section{LITERATURE CITED}

Aarts, N., Metz, M., Holub, E., Staskawicz, B. J., Daniels, M. J., and Parker, J. E. 1998. Different requirements for EDS1 and NDR1 by disease resistance genes define at least two $R$ gene-mediated signaling pathways in Arabidopsis. Proc. Natl. Acad. Sci. U.S.A. 95:10306-10311.

Almagro, L., Gómez Ros, L. V., Belchi-Navarro, S., Bru, R., Ros Barceló, A., and Pedreño, M. A. 2009. Class III peroxidases in plant defence reactions. J. Exp. Bot. 60:377-390.

Asai, T., Tena, G., Plotnikova, J., Willmann, M. R., Chiu, W. L., GomezGomez, L., Boller, T., Ausubel, F. M., and Sheen, J. 2002. MAP kinase signalling cascade in Arabidopsis innate immunity. Nature 415:977-983.

Ascencio-Ibáñez, J. T., Sozzani, R., Lee, T. J., Chu, T. M., Wolfinger, R. D., Cella, R., and Hanley-Bowdoin, L. 2008. Global analysis of Arabidopsis gene expression uncovers a complex array of changes impacting pathogen response and cell cycle during geminivirus infection. Plant Physiol. 148:436-454.

Azevedo, C., Sadanandom, A., Kitagawa, K., Freialdenhoven, A., Shirasu, K., and Schulze-Lefert, P. 2002. The RAR1 interactor SGT1, an essential component of $R$ gene-triggered disease resistance. Science 295:2073-2076.

Byeon, Y., and Back, K. 2014. An increase in melatonin in transgenic rice causes pleiotropic phenotypes, including enhanced seedling growth, delayed flowering, and low grain yield. J. Pineal Res. 56:408-414.

Cheema, S. S., Kapur, S. P., and Chohan, J. S. 1982. Evaluation of rough lemon strains and other rootstocks against greening-disease of citrus. Sci. Hortic. (Amsterdam) 18:71-75.

Clarke, C. R., Chinchilla, D., Hind, S. R., Taguchi, F., Miki, R., Ichinose, Y., Martin, G. B., Leman, S., Felix, G., and Vinatzer, B. A. 2013. Allelic variation in two distinct Pseudomonas syringae flagellin epitopes modulates the strength of plant immune responses but not bacterial motility. New Phytol. 200:847-860.
Côté, F., Cutt, J. R., Asselin, A., and Klessig, D. F. 1991. Pathogenesis-related acidic $\beta$-1,3-glucanase genes of tobacco are regulated by both stress and developmental signals. Mol. Plant-Microbe Interact. 4:173-181.

Duan, Y., Zhou, L., Hall, D. G., Li, W., Doddapaneni, H., Lin, H., Liu, L., Vahling, C. M., Gabriel, D. W., Williams, K. P., Dickerman, A., Sun, Y., and Gottwald, T. 2009. Complete genome sequence of citrus Huanglongbing bacterium, 'Candidatus Liberibacter asiaticus' obtained through metagenomics. Mol. Plant-Microbe Interact. 22:1011-1020.

Felix, G., Duran, J. D., Volko, S., and Boller, T. 1999. Plants have a sensitive perception system for the most conserved domain of bacterial flagellin. Plant J. 18:265-276.

Folimonova, S. Y., Robertson, C. J., Garnsey, S. M., Gowda, S., and Dawson, W. O. 2009. Examination of the responses of different genotypes of citrus to Huanglongbing (citrus greening) under different conditions. Phytopathology 99:1346-1354.

Fu, D. Q., Ghabrial, S., and Kachroo, A. 2009. GmRAR1 and GmSGT1 are required for basal, $R$ gene-mediated and systemic acquired resistance in soybean. Mol. Plant-Microbe Interact. 22:86-95.

Fu, Z. Q., Yan, S., Saleh, A., Wang, W., Ruble, J., Oka, N., Mohan, R., Spoel, S. H., Tada, Y., Zheng, N., and Dong, X. 2012. NPR3 and NPR4 are receptors for the immune signal salicylic acid in plants. Nature 486:228-232.

Gómez-Gómez, L., Bauer, Z., and Boller, T. 2001. Both the extracellular leucine-rich repeat domain and the kinase activity of FSL2 are required for flagellin binding and signaling in Arabidopsis. Plant Cell 13:1155-1163.

Gómez-Gómez, L., Felix, G., and Boller, T. 1999. A single locus determines sensitivity to bacterial flagellin in Arabidopsis thaliana. Plant J. 18:277-284

Halbert, S. E., and Manjunath, K. L. 2004. Asian citrus psyllids (Sternorrhyncha: Psyllidae) and greening disease of citrus: A literature review and assessment of risk in Florida. Fla. Entomol. 87:330-353.

Hao, G., Pitino, M., Ding, F., Lin, H., Stover, E., and Duan, Y. 2014. Induction of innate immune responses by flagellin from the intracellular bacterium, 'Candidatus Liberibacter solanacearum'. BMC Plant Biol. 14:211.

Huot, B., Yao, J., Montgomery, B. L., and He, S. Y. 2014. Growth-defense tradeoffs in plants: A balancing act to optimize fitness. Mol. Plant 7: 1267-1287.

Jung, H. W., Tschaplinski, T. J., Wang, L., Glazebrook, J., and Greenberg, J. T. 2009. Priming in systemic plant immunity. Science 324:89-91.

Kilian, J., Whitehead, D., Horak, J., Wanke, D., Weinl, S., Batistic, O., D'Angelo, C., Bornberg-Bauer, E., Kudla, J., and Harter, K. 2007. The AtGenExpress global stress expression data set: Protocols, evaluation and model data analysis of UV-B light, drought and cold stress responses. Plant J. 50:347-363.

Lai, Z., Schluttenhofer, C. M., Bhide, K., Shreve, J., Thimmapuram, J., Lee, S. Y., Yun, D. J., and Mengiste, T. 2014. MED18 interaction with distinct transcription factors regulates multiple plant functions. Nat. Commun. 5:3064.

Langmead, B., and Salzberg, S. L. 2012. Fast gapped-read alignment with Bowtie 2. Nat. Methods 9:357-359.

Lee, H. Y., Byeon, Y., and Back, K. 2014. Melatonin as a signal molecule triggering defense responses against pathogen attack in Arabidopsis and tobacco. J. Pineal Res. 57:262-268.

Li, H., Handsaker, B., Wysoker, A., Fennell, T., Ruan, J., Homer, N., Marth, G., Abecasis, G., Durbin, R., and 1000 Genome Project Data Processing Subgroup. 2009. The sequence alignment/map format and SAMtools. Bioinformatics 25:2078-2079.

Livak, K. J., and Schmittgen, T. D. 2001. Analysis of relative gene expression data using real-time quantitative PCR and the $2^{-\Delta \Delta C(T)}$ method. Methods 25:402-408.

Lotan, T., Ori, N., and Fluhr, R. 1989. Pathogenesis-related proteins are developmentally regulated in tobacco flowers. Plant Cell 1:881-887.

Mafra, V., Kubo, K. S., Alves-Ferreira, M., Ribeiro-Alves, M., Stuart, R. M., Boava, L. P., Rodrigues, C. M., and Machado, M. A. 2012. Reference genes for accurate transcript normalization in citrus genotypes under different experimental conditions. PLoS One 7:e31263.

Mafra, V., Martins, P. K., Francisco, C. S., Ribeiro-Alves, M., Freitas-Astúa, J., and Machado, M. A. 2013. Candidatus Liberibacter americanus induces significant reprogramming of the transcriptome of the susceptible citrus genotype. BMC Genomics 14:247.

Martin, M. 2011. Cutadapt removes adapter sequences from highthroughput sequencing reads. EMBnet J. 17:10-12.

Martinelli, F., Reagan, R. L., Uratsu, S. L., Phu, M. L., Albrecht, U., Zhao, W., Davis, C. E., Bowman, K. D., and Dandekar, A. M. 2013. Gene regulatory networks elucidating Huanglongbing disease mechanisms. PLoS One 8:e74256.

Martinelli, F., Uratsu, S. L., Albrecht, U., Reagan, R. L., Phu, M. L., Britton, M., Buffalo, V., Fass, J., Leicht, E., Zhao, W., Lin, D., D’Souza, R., Davis, C. E., Bowman, K. D., and Dandekar, A. M. 2012. Transcriptome profiling of citrus fruit response to Huanglongbing disease. PLoS One 7:e38039. 
Mauch, F., Hadwiger, L. A., and Boller, T. 1988. Antifungal hydrolases in pea tissue. 1. Purification and characterization of 2 chitinases and 2 $\beta$-1,3-glucanases differentially regulated during development and in response to fungal infection. Plant Physiol. 87:325-333.

Mauch-Mani, B., and Slusarenko, A. J. 1996. Production of salicylic acid precursors is a major function of phenylalanine ammonia-lyase in the resistance of arabidopsis to Peronospora parasitica. Plant Cell 8:203-212.

Navarro, L., Zipfel, C., Rowland, O., Keller, I., Robatzek, S., Boller, T., and Jones, J. D. G. 2004. The transcriptional innate immune response to flg22. Interplay and overlap with Avr gene-dependent defense responses and bacterial pathogenesis. Plant Physiol. 135:1113-1128.

Park, S., and Back, K. 2012. Melatonin promotes seminal root elongation and root growth in transgenic rice after germination. J. Pineal Res. 53: 385-389.

Parker, J. K., Wisotsky, S. R., Johnson, E. G., Hijaz, F. M., Killiny, N., Hilf, M. E., and De La Fuente, L. 2014. Viability of 'Candidatus Liberibacter asiaticus' prolonged by addition of citrus juice to culture medium. Phytopathology 104:15-26.

Passardi, F., Cosio, C., Penel, C., and Dunand, C. 2005. Peroxidases have more functions than a Swiss army knife. Plant Cell Rep. 24:255-265.

Peart, J. R., Lu, R., Sadanandom, A., Malcuit, I., Moffett, P., Brice, D. C., Schauser, L., Jaggard, D. A. W., Xiao, S., Coleman, M. J., Dow, M., Jones, J. D. G., Shirasu, K., and Baulcombe, D. C. 2002. Ubiquitin ligase-associated protein SGT1 is required for host and nonhost disease resistance in plants. Proc. Natl. Acad. Sci. U.S.A. 99:10865-10869.

Pitino, M., Armstrong, C. M., Cano, L. M., and Duan, Y. 2016. Transient expression of Candidatus Liberibacter asiaticus effector induces cell death in Nicotiana benthamiana. Front. Plant Sci. 7:982.

Pitino, M., Armstrong, C. M., and Duan, Y. 2015. Rapid screening for citrus canker resistance employing pathogen-associated molecular patterntriggered immunity responses. Hortic Res 2:15042.

Rashid, A., and Deyholos, M. K. 2011. PELPK1 (At5g09530) contains a unique pentapeptide repeat and is a positive regulator of germination in Arabidopsis thaliana. Plant Cell Rep. 30:1735-1745.

Rohde, A., Morreel, K., Ralph, J., Goeminne, G., Hostyn, V., De Rycke, R., Kushnir, S., Van Doorsselaere, J., Joseleau, J. P., Vuylsteke, M., Van Driessche, G., Van Beeumen, J., Messens, E., and Boerjan, W. 2004. Molecular phenotyping of the pal1 and pal2 mutants of Arabidopsis thaliana reveals far-reaching consequences on phenylpropanoid, amino acid, and carbohydrate metabolism. Plant Cell 16:2749-2771.

Rosli, H. G., Zheng, Y., Pombo, M. A., Zhong, S., Bombarely, A., Fei, Z., Collmer, A., and Martin, G. B. 2013. Transcriptomics-based screen for genes induced by flagellin and repressed by pathogen effectors identifies a cell wall-associated kinase involved in plant immunity. Genome Biol. 14:R139.

Schneider, H. 1968. Anatomy of greening-diseased sweet orange shoots. Phytopathology 58:1155.

Sechler, A., Schuenzel, E. L., Cooke, P., Donnua, S., Thaveechai, N., Postnikova, E., Stone, A. L., Schneider, W. L., Damsteegt, V. D., and Schaad, N. W. 2009. Cultivation of 'Candidatus Liberibacter asiaticus', 'Ca. L. africanus', and ' $\mathrm{Ca}$. L. americanus' associated with Huanglongbing. Phytopathology 99:480-486.

Shi, H., Chen, Y., Tan, D. X., Reiter, R. J., Chan, Z., and He, C. 2015 a. Melatonin induces nitric oxide and the potential mechanisms relate to innate immunity against bacterial pathogen infection in Arabidopsis. J. Pineal Res. 59:102-108.

Shi, Q., Febres, V. J., Jones, J. B., and Moore, G. A. 2015b. Responsiveness of different citrus genotypes to the Xanthomonas citri ssp. citri-derived pathogen-associated molecular pattern (PAMP) flg22 correlates with resistance to citrus canker. Mol. Plant Pathol. 16:507-520.

Shi, Q., Febres, V. J., Jones, J. B., and Moore, G. A. 2016. A survey of FLS2 genes from multiple citrus species identifies candidates for enhancing disease resistance to Xanthomonas citri ssp. citri. Hortic Res 3:16022.

Sottosanto, J. B., Gelli, A., and Blumwald, E. 2004. DNA array analyses of Arabidopsis thaliana lacking a vacuolar $\mathrm{Na}^{+} / \mathrm{H}^{+}$antiporter: Impact of AtNHX1 on gene expression. Plant J. 40:752-771.

Stover, E., Hall, D. G., Shatters, R. G., and Moore, G. A. 2016a. Influence of citrus source and test genotypes on inoculations with Candidatus Liberibacter asiaticus. HortScience 51:805-809.
Stover, E., Inch, S., Richardson, M. L., and Hall, D. G. 2016b. Conventional citrus of some scion/rootstock combinations show field tolerance under high Huanglongbing disease pressure. HortScience 51:127-132.

Stover, E., and McCollum, G. 2011. Incidence and severity of Huanglongbing and Candidatus Liberibacter asiaticus titer among field-infected citrus cultivars. HortScience 46:1344-1348.

Stover, E., McCollum, G., Ramos, J., and Shatters, R. G. 2015. Growth, health and Liberibacter asiaticus titer in diverse citrus scions on mandarin versus trifoliate hybrid rootstocks in a field planting with severe Huanglongbing. Proc. FL State Hortic. 127:53-59.

Tena, G., Boudsocq, M., and Sheen, J. 2011. Protein kinase signaling networks in plant innate immunity. Curr. Opin. Plant Biol. 14:519-529.

van Loon, L. C., Rep, M., and Pieterse, C. M. J. 2006. Significance of inducible defense-related proteins in infected plants. Annu. Rev. Phytopathol. 44: 135-162.

Wang, Y., Zhou, L., Yu, X., Stover, E., Luo, F., and Duan, Y. 2016. Transcriptome profiling of Huanglongbing (HLB) tolerant and susceptible citrus plants reveals the role of basal resistance in HLB tolerance. Front. Plant Sci. 7:933.

Wu, G. A., Prochnik, S., Jenkins, J., Salse, J., Hellsten, U., Murat, F., Perrier, X., Ruiz, M., Scalabrin, S., Terol, J., Takita, M. A., Labadie, K., Poulain, J., Couloux, A., Jabbari, K., Cattonaro, F., Del Fabbro, C., Pinosio, S., Zuccolo, A., Chapman, J., Grimwood, J., Tadeo, F. R., Estornell, L. H., Muñoz-Sanz, J. V., Ibanez, V., Herrero-Ortega, A., Aleza, P., Pérez-Pérez, J., Ramón, D., Brunel, D., Luro, F., Chen, C., Farmerie, W. G., Desany, B., Kodira, C., Mohiuddin, M., Harkins, T., Fredrikson, K., Burns, P., Lomsadze, A., Borodovsky, M., Reforgiato, G., Freitas-Astúa, J., Quetier, F., Navarro, L., Roose, M., Wincker, P., Schmutz, J., Morgante, M., Machado, M. A., Talon, M., Jaillon, O., Ollitrault, P., Gmitter, F., and Rokhsar, D. 2014. Sequencing of diverse mandarin, pummelo and orange genomes reveals complex history of admixture during citrus domestication. Nat. Biotechnol. 32:656-662.

Wulff, N. A., Zhang, S., Setubal, J. C., Almeida, N. F., Martins, E. C., Harakava, R., Kumar, D., Rangel, L. T., Foissac, X., Bové, J. M., and Gabriel, D. W. 2014. The complete genome sequence of 'Candidatus Liberibacter americanus', associated with citrus Huanglongbing. Mol. Plant-Microbe Interact. 27:163-176.

Xie, Z., Fan, B., Chen, C., and Chen, Z. 2001. An important role of an inducible RNA-dependent RNA polymerase in plant antiviral defense. Proc. Natl. Acad. Sci. U.S.A. 98:6516-6521.

Yan, Q., Sreedharan, A., Wei, S., Wang, J., Pelz-Stelinski, K., Folimonova, S., and Wang, N. 2013. Global gene expression changes in Candidatus Liberibacter asiaticus during the transmission in distinct hosts between plant and insect. Mol. Plant Pathol. 14:391-404.

Yao, J. Q., and Yu, F. 2011. DEB: A web interface for RNA-seq digital gene expression analysis. Bioinformation 7:44-45.

Yonekura-Sakakibara, K., Nakabayashi, R., Sugawara, S., Tohge, T., Ito, T., Koyanagi, M., Kitajima, M., Takayama, H., and Saito, K. 2014. A flavonoid 3-O-glucoside: $2^{\prime \prime}-O$-glucosyltransferase responsible for terminal modification of pollen-specific flavonols in Arabidopsis thaliana. Plant J. 79:769-782.

Yun, B. W., Atkinson, H. A., Gaborit, C., Greenland, A., Read, N. D., Pallas, J. A., and Loake, G. J. 2003. Loss of actin cytoskeletal function and EDS1 activity, in combination, severely compromises non-host resistance in Arabidopsis against wheat powdery mildew. Plant J. 34:768-777.

Zhang, J., Lu, H., Li, X., Li, Y., Cui, H., Wen, C. K., Tang, X., Su, Z., and Zhou, J. M. 2010. Effector-triggered and pathogen-associated molecular pattern-triggered immunity differentially contribute to basal resistance to Pseudomonas syringae. Mol. Plant-Microbe Interact. 23:940-948.

Zou, H., Gowda, S., Zhou, L., Hajeri, S., Chen, G., and Duan, Y. 2012. The destructive citrus pathogen, 'Candidatus Liberibacter asiaticus' encodes a functional flagellin characteristic of a pathogen-associated molecular pattern. PLoS One 7:e46447.

\section{AUTHOR-RECOMMENDED INTERNET RESOURCE}

Citrus Genome database: https://www.citrusgenomedb.org/species/clementina/genome1.0 